\title{
Food Safety Practice and Its Associated Factors among Mothers in Debarq Town, Northwest Ethiopia: Community-Based Cross-Sectional Study
}

\author{
Henok Dagne $(\mathbb{D}$, R. P. Raju, Zewudu Andualem (D), Tesfaye Hagos, and Kidstemariam Addis \\ Department of Environmental and Occupational Health and Safety, Institute of Public Health, College of Medicine and Health Sciences, \\ University of Gondar, Ethiopia
}

Correspondence should be addressed to Henok Dagne; enoch2313@gmail.com

Received 25 February 2019; Revised 17 May 2019; Accepted 22 May 2019; Published 4 June 2019

Academic Editor: Stanley Brul

Copyright (C) 2019 Henok Dagne et al. This is an open access article distributed under the Creative Commons Attribution License, which permits unrestricted use, distribution, and reproduction in any medium, provided the original work is properly cited.

Background. Food safety practice is an important Public Health issue to prevent or control food-borne illnesses. Evidence shows that 10 to $20 \%$ of food-borne diseases outbreaks are because of contamination by food handlers in restaurants, butcher shops, markets, etc. However, the food safety practice and associated factors among mothers who are the food handlers at their homes are not well studied and understood. This study aimed to assess food safety practice and associated factors among mothers in Debarq town. Methods. A community-based cross-sectional study was conducted during March and April, 2018. Four hundred and twenty-three study participants were included using simple random sampling techniques. A structured questionnaire was used to collect data. Multivariable binary logistic regression analysis was used to identify factors associated with food safety practice based on AOR with $95 \%$ CI and $\mathrm{p}<0.05$. Results. About 210 (49.6\%) of study participants had good food safety practice. Food safety practice of mothers was significantly associated with their educational status; secondary educational status adjusted odds ratio, AOR 3.09, 95\% confidence interval, CI: 1.54, 6.20; College and University education AOR 2.95, 95\% CI: 1.22, 7.12; food safety knowledge AOR 2.49, 95\% CI: 1.41, 4.40; and attitude towards food safety AOR 3.67, 95\% CI: 2.27, 5.94. Conclusion. Half of the study subjects had a good level of self-reported food safety practice and the other half had a poor level. Educational status, food safety knowledge, and attitude towards food safety were the identified factors associated with food safety practice. Improving the knowledge and educational status of the mothers is important to enhance their food safety practices.

\section{Background}

Food safety is an important public health issue to prevent or control food-borne illnesses. In response to the increasing number of food-borne illnesses, governments all over the world are intensifying their efforts to improve food safety [1]. According to the WHO [2], contaminated food contributes to 1.5 billion cases of diarrhoea in children each year, resulting in over three million premature deaths. However, these deaths and illnesses are shared by both developed and developing nations. The Centre for Disease Control and Prevention (CDC) estimated that food-borne diseases caused approximately 76 million illnesses annually among the United States of America's 290 million residents, as well as 325,000 hospitalisations $[3,4]$. The incidence of food-borne diseases is rising in developing countries, as well as in the developed world [5].

The transmission of food-borne diseases is aggravated by unsafe food handling practices of food handlers. Approximately 10 to $20 \%$ of food-borne diseases outbreaks are because of contamination by food handlers [6]. Data about food-borne diseases in African region are still scarce [7, 8]. The role of food handlers in homes, usually mothers, in ensuring food safety at the household level is well accepted but an understanding of the status of their food handling knowledge and practices is needed [9]. Various institutional based cross-sectional studies were conducted in Ethiopia [1014]. However, household food safety practice, particularly of mothers, is rarely studied, and the associated factors are poorly understood in Ethiopia. It is very important to 
understand the interaction of the prevailing food safety, knowledge, and practices of food handlers in reducing foodborne outbreaks [15]. Earlier studies [16-22] have showed that knowledge of food safety is associated with food safety practice. Other studies [23-28] have indicated that food safety and hygiene knowledge may not be translated into food safety practice. Another study showed a negative correlation between knowledge and practice [29]. This may be because surface level knowledge may not contemplate for attitudinal change to the desired level and interpreted into meaningful practice. Attitude plays a significant role in food safety practice [10, 16, 30-32]. Food safety knowledge, attitude, and practice are factors playing a fundamental role in food poisoning outbreaks prevention and control [33]. Therefore, the objectives of this community-based cross-sectional study were to assess food safety practice of mothers and identify associated factors in Debarq town.

\section{Methods}

2.1. Study Design and Description of Study Settings. A community-based cross-sectional study was conducted during March and April 2018 in Debarq town. Debarq is located in North Gondar zone in the northern part of Ethiopia in Amhara National Regional State $831 \mathrm{~km}$ from Addis Ababa (the country's capital). The 2018 estimate of population in Debarq town was 24,700 in $108.11 \mathrm{~km}^{2}$ [34]. A pretested structured questionnaire adapted from different literature $[10-13,35]$ was used to collect data. The questionnaire comprised questions about the sociodemographic characteristics of the study participants, 12 questions (washing hands after touching unwrapped raw foods, before food preparation, before touching cooked foods, after handling raw meat, after toilet visit, after sneezing or blowing nose with soap and water, wash raw food items and utensils before use, clean and sanitise food contact surfaces, separately store food and chemicals, wear jewellery when serving food, wear a hat or head covering when serving food, and prepare food with whenever a wound is on the hand) about their food safety practices with a 4-scale Likert (1-always, 2-usually, 3-sometimes, and 4-never), 10 questions (yes/no) about their knowledge of food safety (potential sources of food contamination, cross-contamination, microbial contamination, transmission of food-borne disease, personal hygiene and food-borne disease, food preservation techniques, safe food handling, person-to-person food-borne disease transmission, and hand washing knowledge), and 9 attitudinal questions with 5-scale Likert (0-strongly disagree, 1-disagree, 2-neutral, 3-agree, and 4- strongly agree). Two undergraduate students studying Environmental Health trained about the contents of a data collection tool, data collection methods, and interviewing techniques for two days were involved in the data collection process. They visited residential houses in Debarq town, interviewed 423 food handling mothers, filled the questionnaire, and rechecked and corrected the data before they left each house. Two supervisors supervised the overall interview process and daily checked the completeness, quality, and consistency of the data.
2.2. Source Population. All mothers in Debarq town served as a source population for the current study.

2.3. Study Population. Simple random sampling technique was used to select study participants. These randomly selected mothers in Debarq town were a study population for the current research.

2.4. Inclusion and Exclusion Criteria. Four hundred and twenty-three mothers who take part in food handling operation and who have stayed at least for 6 months in the household in Debarq town were included in the study. Mothers who were seriously ill and who did not take part in food handling because of different reasons or absent during data collection were excluded from the study.

2.5. Sample Size Determination and Sampling Procedure. Single population proportion formula was used to determine the sample size with the assumptions that the probability of food safety practice among mothers $p=50 \%$ because there were no other similar previous studies in Ethiopia, 95\% confidence interval (CI), and 5\% margin of error (d).

$$
\begin{aligned}
n & =\frac{\left(z_{a / 2}\right)^{2} \times p \times(1-p)}{d^{2}}=\frac{(1.96)^{2} \times 0.5 \times(1-0.5)}{(0.05)^{2}} \\
& =384
\end{aligned}
$$

By adding 10\% nonresponse rate the sample size comprises 423 mothers who participated in the study. Simple random sampling technique was used to select those study participants.

2.6. Data Management and Statistical Analysis. Data were entered using EPI-INFO version 7 and exported into SPSS version 20 for further analysis. For most variables, data were presented by frequencies and percentages. The variables found having a p-value less than 0.2 in the bivariable analysis were further analysed by multivariable logistic regression for controlling the effect of confounders. The variables that had a significant association with food safety practice of mothers were identified based on adjusted odds ratio (AOR) with $95 \%$ confidence interval $(\mathrm{CI})$ and $\mathrm{p}<0.05$.

\subsection{Operational Definitions}

2.7.1. Food Safety Practice Level. The respondents who scored less than or equal to the mean value of their responses to 12 food safety practice related questions were considered as having "poor level of practice." Those who scored more than the mean value were considered as having "good level of practice" $[13,14,36]$.

2.7.2. Food Safety Knowledge Level. The respondents who scored less than or equal to the mean value of their responses to 10 food safety knowledge related questions were considered as having "poor level of knowledge." Those who scored more 


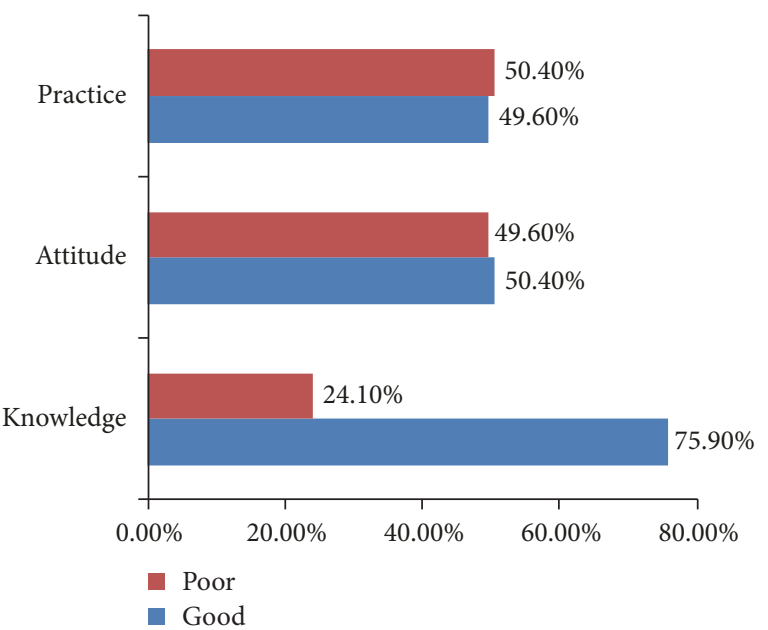

FIGURE 1: Food safety knowledge, attitude, and practice level of mothers in Debarq town, northwest Ethiopia, March - April 2018.

than the mean value were considered as having "good level of knowledge" $[13,14,36]$.

2.7.3. Food Safety Attitude Level. The respondents who scored less than or equal to the mean value of their responses to 9 questions about their attitude towards food safety were considered as having "poor level of attitude." Those who scored more than the mean value were considered as having "good level of attitude" [13].

\section{Results}

3.1. Sociodemographic Information. All the 423 study participants responded to the questionnaire, thus resulting in 100\% response rate. The mean $( \pm \mathrm{SD})$ age of the study participant was $39.84 \pm 1.10$ years. One hundred seventy-two (40.7\%) of the respondents could not read and write. The mean monthly income of respondents was Ethiopian birr (ETB) 1687.9 (approximately, US dollars 62.5 at the rate of USD $1=$ ETB 27). Only ninety-one (21.5\%) of the study participants have attended informal food safety training during the years 2016-2018 (Table 1).

3.2. Food Safety Knowledge, Attitude, and Practice Levels of Mothers. Of the 423 respondents, $321(75.9 \%)$ had a good level of knowledge, and $213(50.4 \%)$ had a good level of attitude about the food safety whereas $210(49.6 \%)$ mothers had a good level of food safety practice and 213 (50.4\%) had a poor level of self-reported practice (Figure 1).

3.3. Factors Associated with Food Safety Practice of Mothers. Age, marital status, income, educational status, food safety training experience, family size, knowledge, and attitude of mothers about food safety had p-values less than 0.2 in the bivariable logistic regression. Of these factors, only educational status, knowledge, and attitude were significantly associated with food safety practice in the multivariable regression analysis (Table 2).
As compared with the mothers who cannot read and write, the probability of a good level of self-reported food safety practice among mothers who had secondary educational status was 3.09 times higher [AOR 3.09, 95\% CI: 1.54, 6.20] and among mothers who had college and university level educational status 2.95 times higher [AOR 2.95, 95\% CI: $1.22,7.12]$.

The odds of food safety practice were 2.49 times higher [AOR 2.49, 95\% CI: 1.41, 4.40] among mothers who had a good level of knowledge than those who had a poor level of knowledge.

The probability of food safety practice was 3.67 times higher [AOR 3.67, 95\% CI: 2.27, 5.94] among mothers who had a good level of attitude towards food safety than those who had a poor level of attitude.

\section{Discussion}

Only $49.6 \%$ of the study participants in the current study had a good level of food safety practice. This is lower than studies conducted among food vendors in north central Nigeria [37], Sri Lanka [38], and Khaza bazar, India [39], but higher than studies conducted in Arba Minch, Ethiopia [14]. This discrepancy might be because of the difference in the study period, sample size, and sociodemographic conditions of the study subjects.

The study participants have higher food safety knowledge score as compared to their attitude and practice. This study showed that $75.9 \%$ of the study subjects had a good knowledge which was higher than studies conducted among Saudi Arabia mothers [40], youth in Malaysia [41], Cassava processors in Nigeria [42], women working in Alexandria University, Egypt [43], and women of Khaza bazar, India [39], and amongst food handlers in the Republic of Ireland [44]. This difference might be because of the time of the study, different tools used to assess the level of knowledge, sample size, and socioeconomic difference among the study units.

About $50.4 \%$ of the study subjects in the current study had a good attitude. This result is lower than a study conducted in Ghana Acra [45] and India [39] but in line with a study conducted in Nigeria [42]. The difference might be because of the time of the data and method used in the current study is self-reported which might be affected by social desirability bias.

Good level of food safety practice of mothers in Debarq town was associated with good levels of educational status, knowledge, and attitude. However, only about half the number of study participant mothers (49.6\%) had a good level of food safety practice and the other half $(50.4 \%)$ had a poor level. Thus, the risk of occurrence of food-borne illnesses to the household members, including children with under-five years of age as they are least resistant to food-borne diseases, may be at least $50 \%$ as they are likely to be exposed to the unsafe food available because of the poor level of food safety practice of $50 \%$ of the food handling mothers at households.

The food safety practice was significantly associated with the educational status of mothers. The food safety practice was higher among study subjects with secondary school and 
TABLE 1: Sociodemographic information of study participants in Debarq town, northwest Ethiopia, March - April 2018.

\begin{tabular}{|c|c|c|}
\hline Sociodemographic variables & Frequency $(\mathrm{n})$ & Percent (\%) \\
\hline \multicolumn{3}{|l|}{ Age } \\
\hline $18-31$ years & 114 & 27.0 \\
\hline $32-40$ years & 118 & 27.9 \\
\hline $41-48$ years & 89 & 21.0 \\
\hline $49-80$ years & 102 & 24.1 \\
\hline \multicolumn{3}{|l|}{ Educational status } \\
\hline Cannot read or write & 172 & 40.7 \\
\hline Primary education & 96 & 22.7 \\
\hline Secondary education & 84 & 19.9 \\
\hline College or University & 71 & 16.8 \\
\hline \multicolumn{3}{|l|}{ Marital status } \\
\hline Single & 65 & 15.4 \\
\hline Married & 242 & 57.2 \\
\hline Divorced & 57 & 13.5 \\
\hline Widowed & 59 & 13.9 \\
\hline \multicolumn{3}{|l|}{ Average monthly income } \\
\hline $200-800$ & 111 & 26.2 \\
\hline $801-1100$ & 103 & 24.3 \\
\hline $1101-2145$ & 104 & 24.6 \\
\hline$>2145$ & 105 & 24.8 \\
\hline \multicolumn{3}{|l|}{ Religion } \\
\hline Christian & 333 & 78.7 \\
\hline Muslim & 90 & 21.3 \\
\hline \multicolumn{3}{|l|}{ Ethnicity } \\
\hline Amhara & 391 & 92.4 \\
\hline Qimant & 21 & 5.0 \\
\hline Others & 11 & 2.6 \\
\hline \multicolumn{3}{|l|}{ Family size } \\
\hline $2-5$ & 310 & 73.3 \\
\hline$>5$ & 113 & 26.7 \\
\hline \multicolumn{3}{|l|}{ Ever heard about food safety } \\
\hline Yes & 333 & 78.7 \\
\hline No & 90 & 21.3 \\
\hline \multicolumn{3}{|c|}{ Ever attended food safety training } \\
\hline Yes & 142 & 33.6 \\
\hline No & 281 & 66.4 \\
\hline \multicolumn{3}{|c|}{ Attended food safety training in the past two years $(n=142)$} \\
\hline Yes & 91 & 21.5 \\
\hline No & 332 & 78.5 \\
\hline
\end{tabular}

above educational status. This result is in line with different earlier studies [40, 46-48].

Mothers with a good score of knowledge level had better food safety practice. This is in line with earlier studies $[13,16$, $30,39,49]$. Study subjects with a good score of attitude toward food safety also had reported better food safety practice. This finding is more or less similar with earlier studies [41, 50]. However, the scores for both the good and poor levels of attitude and practice remained at about $50 \%$ that is far below the score of a good level of knowledge (75.9\%). Thus, considerable gap exists between the level of knowledge on the one hand and the levels of attitude and practice among mothers in Debarq. More or less similar gap in hand washing knowledge and practice prevails in other places in Ethiopia $[35,51,52]$. Not only does the disparity between the food safety related knowledge and practice exist in Ethiopia but it is a phenomenon in other developing countries as well [5357].

Training was not associated with the food safety practice of mothers in the current study. This absence of association does not mean that training was not an important factor. However, there could be other reasons that did not make the 
TABLE 2: Bivariable and multivariable logistic regression analysis of factors associated with food safety practice among mothers of Debarq town, northwest Ethiopia, March - April 2018.

\begin{tabular}{|c|c|c|c|c|}
\hline \multirow{2}{*}{ Variables } & \multicolumn{2}{|c|}{ Practice } & \multirow{2}{*}{ COR with 95\% CI } & \multirow{2}{*}{ AOR with 95\% CI } \\
\hline & Good & poor & & \\
\hline \multicolumn{5}{|l|}{$\overline{\text { Age }}$} \\
\hline $18-31$ & 71 & 43 & $3.03(1.74,5.28)$ & $1.20(0.56,2.60)$ \\
\hline $32-40$ & 66 & 52 & $2.33(1.35,4.01)$ & $1.16(0.57,2.33)$ \\
\hline $41-48$ & 37 & 52 & $1.30(0.73,2.34)$ & $0.81(0.40,1.64)$ \\
\hline $49-80$ & 36 & 66 & 1 & \\
\hline \multicolumn{5}{|l|}{ Marital status } \\
\hline Single & 41 & 24 & $2.04(0.99,4.20)$ & $0.95(0.39,2.34)$ \\
\hline Married & 122 & 120 & $1.20(0.68,2.16)$ & $1.12(0.56,2.24)$ \\
\hline Widowed & 21 & 38 & $0.66(0.31,1.39)$ & $0.90(0.37,2.20)$ \\
\hline Divorced & 26 & 31 & 1 & \\
\hline \multicolumn{5}{|l|}{ Monthly income } \\
\hline $200-800$ & 50 & 61 & 1 & \\
\hline $801-1100$ & 47 & 56 & $1.02(0.60,1.76)$ & $0.91(0.49,1.69)$ \\
\hline $1101-2145$ & 50 & 54 & $1.13(0.66,1.93)$ & $0.74(0.39,1.40)$ \\
\hline 2146-11001 & 63 & 42 & $1.83(1.07,3.14)$ & $0.85(0.41,1.75)$ \\
\hline \multicolumn{5}{|l|}{ Educational status } \\
\hline Cannot read and write & 51 & 121 & 1 & \\
\hline Primary & 47 & 49 & $2.28(1.36,3.81)$ & $1.42(0.77,2.60)$ \\
\hline Secondary & 58 & 26 & $5.29(3.00,9.33)$ & $3.09(1.54,6.20)^{* *}$ \\
\hline Diploma and above & 54 & 17 & $7.54(3.99,14.23)$ & $2.95(1.22,7.12)^{*}$ \\
\hline \multicolumn{5}{|c|}{ Ever attended food safety training } \\
\hline Yes & 88 & 54 & $2.12(1.41,3.21)$ & $1.37(0.65,2.88)$ \\
\hline No & 122 & 159 & 1 & \\
\hline \multicolumn{5}{|c|}{ Attended food safety training the past 2 years } \\
\hline Yes & 53 & 38 & $1.56(0.97,2.48)$ & $0.75(0.33,1.69)$ \\
\hline No & 157 & 175 & 1 & \\
\hline \multicolumn{5}{|l|}{ Family size } \\
\hline $1-5$ & 170 & 140 & $2.22(1.42,3.46)$ & $1.51(0.88,2.59)$ \\
\hline $6-12$ & 40 & 73 & 1 & \\
\hline \multicolumn{5}{|l|}{ Knowledge } \\
\hline Good & 183 & 138 & $3.68(2.25,6.03)$ & $2.49(1.41,4.40)^{* *}$ \\
\hline Poor & 27 & 75 & 1 & \\
\hline \multicolumn{5}{|l|}{ Attitude } \\
\hline Good & 151 & 62 & $6.23(4.09,9.50)$ & $3.67(2.27,5.94)^{* * *}$ \\
\hline Poor & 59 & 151 & 1 & \\
\hline
\end{tabular}

${ }^{*}$ Significant $<0.05 ;{ }^{* *}$ significant at $\mathrm{p}<0.01 ;{ }^{* * *}$ significant at $\mathrm{p}<0.001$.

mothers apply their training in practice. Mothers, because of the high workload, sometimes are careless to put the knowledge they have gained into practice. This might also be because food safety training is haphazardly organised and contents of basic food safety knowledge are lacking.

\section{Conclusion}

About half the number of mothers in Debarq town had a good level of self-reported food safety practice and the other half had a poor level. Overall, their food safety practice level was found low as compared with earlier studies. There was no correlation with the level of food safety practice and some demographic variables (age, marital status, income, and family size). Educational status, knowledge, and attitude were identified as the factors having stronger significant association with the food safety practice of mothers. Therefore, improving the educational status, food safety knowledge, and positive attitude of communities, particularly of mothers, through frequent public health awareness campaigns/trainings are important interventions to enhance their level of food safety practice. 
Finally, this research did not include direct observations such as food and drinking water quality storage and handling food, cooking setting, and washing facility at households. Hence, the self-reported food safety practice level of mothers might be high because of social desirability bias. The tool used in this study was not a standard. In addition, because of scarce studies focusing on food safety practice of mothers at household level in both Ethiopia and other countries the comparison of results is difficult.

\section{List of Abbreviations}

AOR: Adjusted odds ratio

CI: Confidence interval

COR: Crude odds ratio

$\mathrm{Km}$ : Kilometre

$\mathrm{Km}^{2}$ : Kilometre square

SD: Standard deviation

SPSS: Statistical Package for Social Sciences.

\section{Data Availability}

The data used to support the findings of this study are available from the corresponding author upon request.

\section{Ethical Approval}

Ethical clearance was obtained from the ethical committee of the Department of Environmental and Occupational Health and Safety of the University of Gondar and an official letter was submitted to the town and kebeles administrators. There were no risks due to participation in this research project. The collected data were used for this research purpose only and kept with complete confidentiality.

\section{Consent}

Verbal informed consent was obtained from the study participants, i.e., mothers. This manuscript contains none of an individual person's data.

\section{Conflicts of Interest}

None of the authors has any competing interests in the manuscript.

\section{Authors' Contributions}

All the authors actively participated during the conception of the research issue, development of a research proposal, data collection, analysis, and interpretation, and writing various parts of the research report. R. P. Raju, Tesfaye Hagos, and Kidstemariam Addis designed the protocol and participate in data collection. Henok Dagne and Zewudu Andualem designed the protocol, participate in data collection, analysed the data, supervised the overall research process, and prepared the manuscript. Tesfaye Hagos and Kidstemariam
Addis entered data into Epi-Info epidemiological software. All the authors read and approved the final manuscript.

\section{Acknowledgments}

The authors are pleased to acknowledge data collectors, field supervisors, study participants, University of Gondar, and Debarq town administrators for their unreserved contributions to the success of this study. The University of Gondar covered questionnaire duplication and data collection fees.

\section{References}

[1] G. M. Subba Rao, R. V. Sudershan, P. Rao, M. Vishnu Vardhana Rao, and K. Polasa, "Food safety knowledge, attitudes and practices of mothers: findings from focus group studies in South India," Appetite, vol. 49, no. 2, pp. 441-449, 2007.

[2] S. Henson and T. Reardon, "Private agri-food standards: Implications for food policy and the agri-food system," Food Policy, vol. 30, no. 3, pp. 241-253, 2005.

[3] J. Kennedy, V. Jackson, I. S. Blair, D. A. McDowell, C. Cowan, and D. J. Bolton, "Food safety knowledge of consumers and the microbiological and temperature status of their refrigerators," Journal of Food Protection, vol. 68, no. 7, pp. 1421-1430, 2005.

[4] M. Mama and G. Alemu, "Prevalence and factors associated with intestinal parasitic infections among food handlers of Southern Ethiopia: cross sectional study," BMC Public Health, vol. 16, no. 105, 2016.

[5] M. Jevšnik, V. Hlebec, and P. Raspor, "Consumers' awareness of food safety from shopping to eating," Food Control, vol. 19, no. 8, pp. 737-745, 2008.

[6] A. B. Mudey, N. Kesharwani, G. A. Mudey, R. C. Goyal, A. K. Dawale, and V. V. Wagh, "Health status and personal hygiene among food handlers working at food establishment around a rural teaching hospital in wardha district of maharashtra, India," Global Journal of Health Science, vol. 2, no. 2, article 198, 2010.

[7] J. M. Wagacha and J. W. Muthomi, "Mycotoxin problem in Africa: Current status, implications to food safety and health and possible management strategies," International Journal of Food Microbiology, vol. 124, no. 1, pp. 1-12, 2008.

[8] K. Schmidt and C. Tirado, WHO Surveillance Programme for Control of Foodborne Infections and Intoxications in Europe: Seventh Report 1993-1998, Federal Institute for Health Protection of Consumers and Veterinary Medicine, 2001.

[9] L. C. Medeiros, V. N. Hillers, G. Chen, V. Bergmann, P. Kendall, and M. Schroeder, "Design and development of food safety knowledge and attitude scales for consumer food safety education," Journal of the Academy of Nutrition and Dietetics, vol. 104, no. 11, pp. 1671-1677, 2004.

[10] F. A. Chekol, M. F. Melak, A. K. Belew, and E. G. Zeleke, "Food handling practice and associated factors among food handlers in public food establishments, Northwest Ethiopia," BMC Research Notes, vol. 12, no. 1, 2019.

[11] Z. Gizaw, M. Gebrehiwot, and Z. Teka, "Food safety practice and associated factors of food handlers working in substandard food establishments in Gondar Town, Northwest Ethiopia, 2013/14," International Journal of Food Sciences and Nutrition, vol. 3, no. 7, pp. 138-146, 2013.

[12] M. Kibret and B. Abera, "The sanitary conditions of food service establishments and food safety knowledge and practices of 
food handlers in bahir dar town," Ethiopian Journal of Health Sciences, vol. 22, no. 1, Article ID 22984329, pp. 27-35, 2012.

[13] A. G. Tessema, K. A. Gelaye, and D. H. Chercos, "Factors affecting food handling practices among food handlers of Dangila town food and drink establishments, North West Ethiopia," BMC Public Health, vol. 14, no. 1, article 571, 2014.

[14] D. Legesse, M. Tilahun, E. Agedew, and D. Haftu, "Food handling practices and associated factors among food handlers in arba minch town public food establishments in Gamo Gofa Zone, Southern Ethiopia," Epidemiology: Open Access, vol. 7, no. 302, 2017 (Bulgarian).

[15] A. Abdullahi, A. Hassan, N. Kadarman, A. Saleh, Y. B. Shu'aibu, and P. L. Lua, "Food safety knowledge, attitude, and practice toward compliance with abattoir laws among the abattoir workers in Malaysia," Journal of General Internal Medicine, vol. 9, pp. 79-87, 2016.

[16] M. M. Rahman, M. T. Arif, K. Bakar, and Z. bt Talib, "Food safety knowledge, attitude and hygiene practices among the street food vendors in Northern Kuching City, Sarawak," Borneo Science, vol. 31, 2016.

[17] F. P. Çakıroğlu and A. Uçar, "Employees' perception of hygiene in the catering industry in Ankara (Turkey)," Food Control, vol. 19, no. 1, pp. 9-15, 2008.

[18] A. C. Iwu, K. A. Uwakwe, C. B. Duru et al., "Knowledge, attitude and practices of food hygiene among food vendors in Owerri, Imo State, Nigeria," Occupational Diseases and Environmental Medicine, vol. 5, no. 1, pp. 11-25, 2017.

[19] I. F. Angelillo, N. M. A. Viggiani, L. Rizzo, and A. Bianco, "Food handlers and foodborne diseases: knowledge, attitudes, and reported behavior in Italy," Journal of Food Protection, vol. 63, no. 3, pp. 381-385, 2000.

[20] J. O. Bamidele, W. O. Adebimpe, E. A. Oladele, and O. A. Adeoye, "Hygiene practices among workers in local eateries of Orolu community in south Western Nigeria," Annals of Medical and Health Sciences Research, vol. 5, no. 4, pp. 235-240, 2015.

[21] N.-A. Abdul-Mutalib, M.-F. Abdul-Rashid, S. Mustafa, S. AminNordin, R. A. Hamat, and M. Osman, "Knowledge, attitude and practices regarding food hygiene and sanitation of food handlers in Kuala Pilah, Malaysia," Food Control, vol. 27, no. 2, pp. 289-293, 2012.

[22] N. A. Al-Shabib, S. H. Mosilhey, and F. M. Husain, "Crosssectional study on food safety knowledge, attitude and practices of male food handlers employed in restaurants of King Saud University, Saudi Arabia," Food Control, vol. 59, pp. 212-217, 2015.

[23] A. Wilcock, M. Pun, J. Khanona, and M. Aung, "Consumer attitudes, knowledge and behaviour: a review of food safety issues," Trends in Food Science \& Technology, vol. 15, no. 2, pp. 56-66, 2004.

[24] M. Baş, A. Şafak Ersun, and G. Kıvanç, “The evaluation of food hygiene knowledge, attitudes, and practices of food handlers' in food businesses in Turkey," Food Control, vol. 17, no. 4, pp. 317$322,2006$.

[25] H. A. Grema, J. Kwaga, M. Bello, and H. U. Onimisi, “Assessment of food hygiene knowledge, attitudes and practices of fish handlers in Kaduna State, Nigeria," Advances in Animal and Veterinary Sciences, vol. 7, no. 3, pp. 131-137, 2018.

[26] D. A. Clayton, C. J. Griffith, P. Price, and A. C. Peters, "Food handlers' beliefs and self-reported practices," International Journal of Environmental Health Research, vol. 12, no. 1, pp. 25-39, 2002.
[27] F. Akabanda, E. H. Hlortsi, and J. Owusu-Kwarteng, "Food safety knowledge, attitudes and practices of institutional foodhandlers in Ghana," BMC Public Health, vol. 17, no. 1, article 40, 2017.

[28] T. Rheinländer, M. Olsen, J. A. Bakang, H. Takyi, F. Konradsen, and H. Samuelsen, "Keeping up appearances: perceptions of street food safety in urban Kumasi, Ghana," Journal of Urban Health, vol. 85, no. 6, pp. 952-964, 2008.

[29] M. Ansari-Lari, S. Soodbakhsh, and L. Lakzadeh, "Knowledge, attitudes and practices of workers on food hygienic practices in meat processing plants in Fars, Iran," Food Control, vol. 21, no. 3, pp. 260-263, 2010.

[30] F. H. Ismail, C. T. Chik, R. Muhammad, and N. M. Yusoff, "Food safety knowledge and personal hygiene practices amongst mobile food handlers in Shah Alam, Selangor," Procedia - Social and Behavioral Sciences, vol. 222, pp. 290-298, 2016.

[31] H. Lee, H. Abdul Halim, K. Thong, and L. Chai, "Assessment of food safety knowledge, attitude, self-reported practices, and microbiological hand hygiene of food handlers," International Journal of Environmental Research and Public Health, vol. 14, no. 1, article 55, 2017.

[32] T.-P. Lim, F. Y. Chye, M. R. Sulaiman, N. M. Suki, and J.-S. Lee, "A structural modeling on food safety knowledge, attitude, and behaviour among bum bum island community of Semporna, Sabah," Food Control, vol. 60, pp. 241-246, 2016.

[33] L. Sharif and T. Al-Malki, "Knowledge, attitude and practice of Taif University students on food poisoning," Food Control, vol. 21, no. 1, pp. 55-60, 2010.

[34] Amhara regional government bureau of finance and economic development statstical bulletin, http://www.amharabofed.gov .et/PDF_Files/stastical_bulletins/1\%20GIS.pdf.

[35] A. Demssie, D. Daniel, A. Tefera, H. Kindu, S. Abebe, and H. Sanbata, "Knowledge, attitude and practice (KAP) of hand washing among mothers of under five children in Gotu Kebele Wondogenet Woreda Oromia, Ethiopia," International Journal of Environmental Science and Technology, vol. 6, no. 4, pp. 146153, 2017.

[36] R. Smith, "Food hygiene training: the chance to create a coherent policy," British Food Journal, vol. 96, no. 7, pp. 41-45, 1994.

[37] T. O. Afolaranmi, Z. I. Hassan, D. A. Bello, and Z. Misari, "Knowledge and practice of food safety and hygiene among food vendors in primary schools in Jos, Plateau State, North Central Nigeria," European Journal of Medical Research, vol. 4, no. 2, pp. 16-22, 2015.

[38] L. S. Galgamuwa, D. Iddawela, and S. D. Dharmaratne, "Knowledge and practices of food hygiene among food handlers in plantation sector, Sri Lanka," International Journal of Scientific Reports, vol. 2, no. 12, pp. 304-311, 2016.

[39] R. R. Mendagudali, K. D. Akka, I. A. Swati, D. T. Shedole, and N. A. Bendigeri, "Knowledge, attitude, and practices of food safety among women of Khaza bazar, the urban field practice area of KBN Institute of Medical Sciences, Kalaburagi, Karnataka," International Journal of Medical Science and Public Health, vol. 5, no. 3, pp. 516-520, 2016.

[40] W. O. Ayaz, A. Priyadarshini, and A. K. Jaiswal, "Food safety knowledge and practices among saudi mothers," Foods, vol. 7, no. 12, article 193, 2018.

[41] F. M. Moy, A. A. Alias, R. Jani, H. Abdul Halim, and W. Y. Low, "Determinants of self-reported food safety practices among youths: a cross-sectional online study in Kuala Lumpur, Malaysia," British Food Journal, vol. 120, no. 4, pp. 891-900, 2018. 
[42] K. Thomas and O. Philips, "Assessment of food safety practices among cassava processors in selected rural communities of Oyo State, Nigeria," African Journal of Food, Agriculture, Nutrition and Development, vol. 15, no. 4, pp. 10317-10334, 2015.

[43] M. Fawzi and M. E. Shama, "Food safety knowledge and practices among women working in Alexandria University, Egypt," The Journal of the Egyptian Public Health Association, vol. 84, no. 1-2, pp. 95-117, 2009.

[44] N. A. Moreb, A. Priyadarshini, and A. K. Jaiswal, "Knowledge of food safety and food handling practices amongst food handlers in the Republic of Ireland," Food Control, vol. 80, pp. 341-349, 2017.

[45] A. Parry-Hanson Kunadu, D. B. Ofosu, E. Aboagye, and K. Tano-Debrah, "Food safety knowledge, attitudes and selfreported practices of food handlers in institutional foodservice in Accra, Ghana," Food Control, vol. 69, pp. 324-330, 2016.

[46] R. Meysenburg, J. A. Albrecht, R. Litchfield, and P. K. RitterGooder, "Food safety knowledge, practices and beliefs of primary food preparers in families with young children. a mixed methods study," Appetite, vol. 73, pp. 121-131, 2014.

[47] R. V. Sudershan, G. M. S. Rao, P. Rao, M. V. V. Rao, and K. Polasa, "Food safety related perceptions and practices of mothers - a case study in Hyderabad, India," Food Control, vol. 19, no. 5, pp. 506-513, 2008.

[48] I. F. Angelillo, M. R. Foresta, C. Scozzafava, and M. Pavia, "Consumers and foodborne diseases: knowledge, attitudes and reported behavior in one region of Italy," International Journal of Food Microbiology, vol. 1-2, Article ID 11252498, pp. 161-166, 2001.

[49] U. M. Asmawi, A. A. Norehan, K. Salikin, N. A. Rosdi, N. A. Munir, and N. B. Basri, "An Assessment of Knowledge, Attitudes and Practices in Food Safety Among Food Handlers Engaged in Food Courts," Current Research in Nutrition and Food Science Journal, vol. 6, no. 2, pp. 346-353, 2018.

[50] L. Yarrow, V. M. Remig, and M. M. Higgins, "Food safety educational intervention positively influences college students food safety attitudes, beliefs, knowledge, and self-reported practices," Journal of Environmental Health, vol. 71, no. 6, pp. 30-35, 2009.

[51] H. Brhanu, D. Negese, and M. Gebrehiwot, "Determinants of acute diarrheal disease among under-five children in pawi hospital, Northwest Ethiopia," American Journal of Pediatrics, vol. 2, no. 2, pp. 29-36, 2017.

[52] T. Abuka, D. Jembere, and D. Tsegaw, "Determinants for acute malnutrition among under-five children at public health facilities in Gedeo Zone, Ethiopia: a case-control study," Pediatrics \& Therapeutics, vol. 7, no. 317, 2017.

[53] B. K. Wodnik, M. C. Freeman, A. S. Ellis, E. Awino Ogutu, A. Webb Girard, and B. A. Caruso, "Development and application of novel caregiver hygiene behavior measures relating to food preparation, handwashing, and play environments in Rural Kenya," International Journal of Environmental Research and Public Health, vol. 15, no. 9, p. 1994, 2018.

[54] V. G. Chellaiyan, L. Fasna, and S. V. Mallika, "Food safety awareness and food handling practices among rural population of Tamil Nadu," International Journal of Community Medicine and Public Health, vol. 5, no. 4, pp. 1441-1447, 2018.

[55] M. C. Freeman, M. E. Stocks, O. Cumming et al., "Hygiene and health: systematic review of handwashing practices worldwide and update of health effects," Tropical Medicine \& International Health, vol. 19, no. 8, pp. 906-916, 2014.
[56] S. E. Rabbi and N. C. Dey, "Exploring the gap between hand washing knowledge and practices in Bangladesh: a crosssectional comparative study," BMC Public Health, vol. 13, no. 1, article 89, 2013.

[57] V. Curtis, W. Schmidt, S. Luby, R. Florez, O. Touré, and A. Biran, "Hygiene: new hopes, new horizons," The Lancet Infectious Diseases, vol. 11, no. 4, pp. 312-321, 2011. 


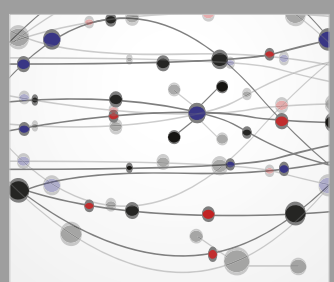

The Scientific World Journal
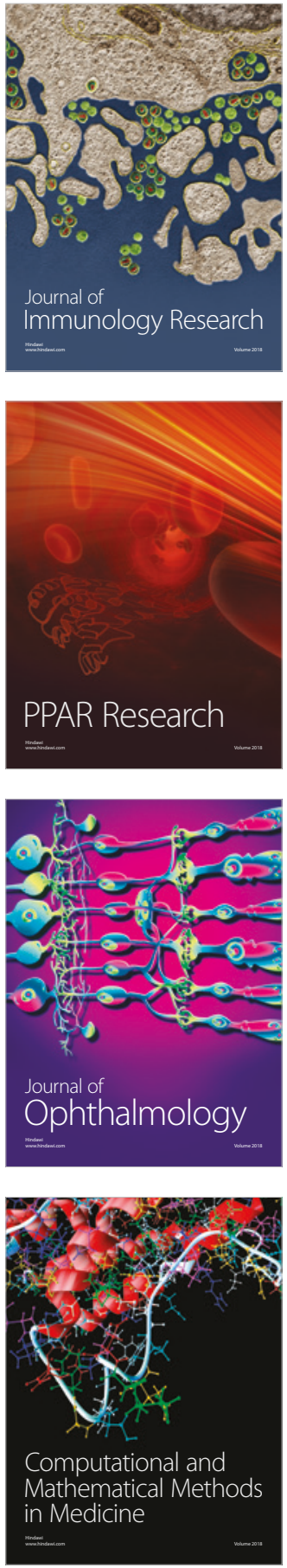

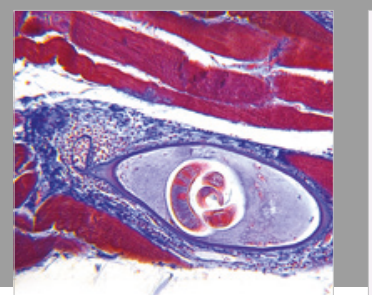

Gastroenterology Research and Practice

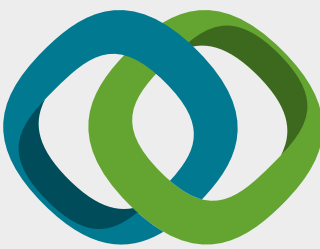

\section{Hindawi}

Submit your manuscripts at

www.hindawi.com
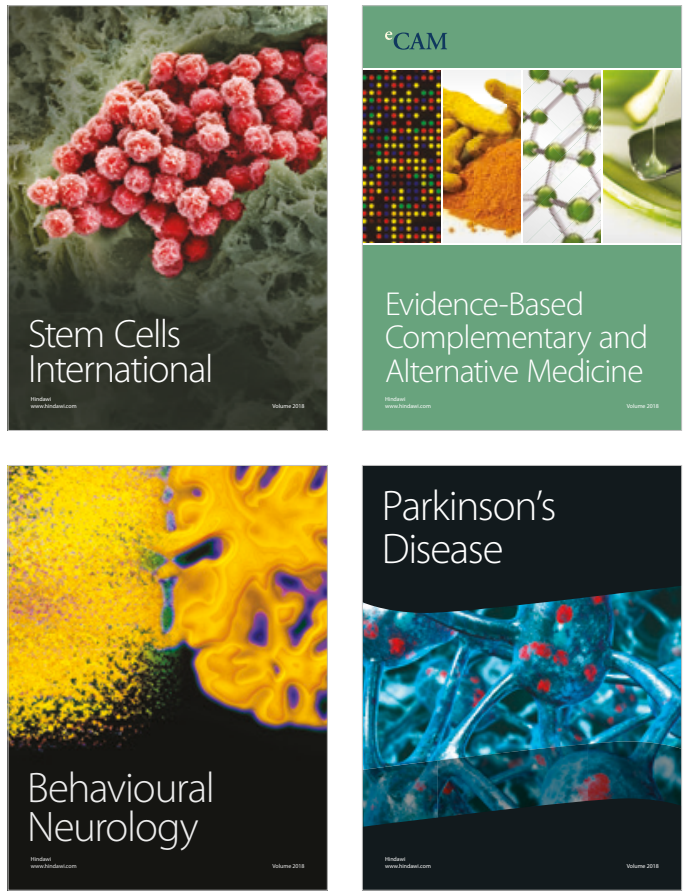

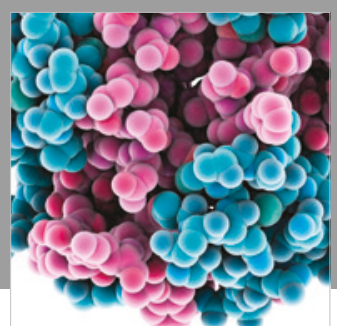

ournal of

Diabetes Research

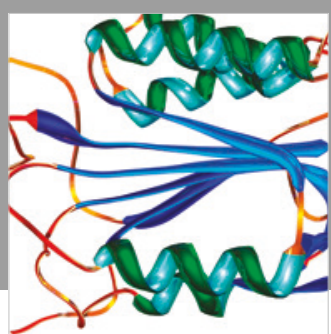

Disease Markers
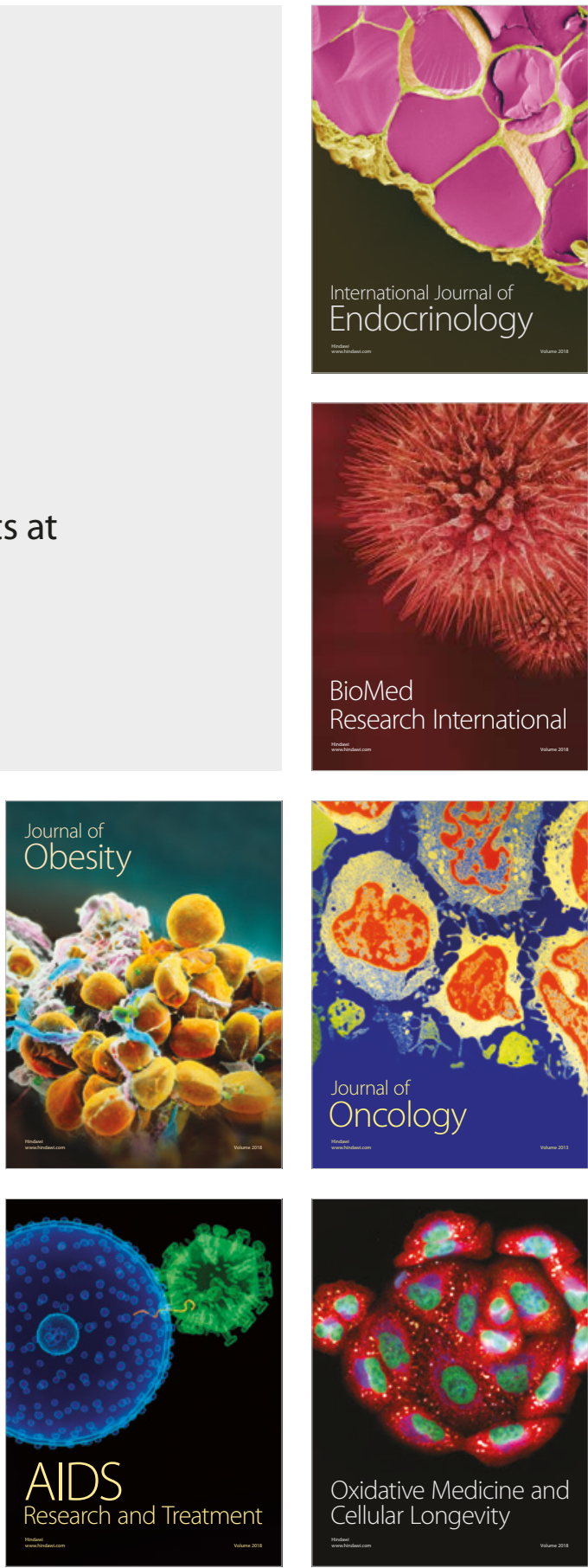